\title{
OS DISPOSITIVOS SIMBÓLICOS UTILIZADOS PARA REAFIRMAÇÃO DA CONDIÇÃO INDÍGENA: UMA ANÁLISE SOB A ÓTICA DO REGIME NOTURNO DA IMAGEM
}

\author{
Heloisa Juncklaus Preis Moraes** \\ Leidiane Coelho Jorge ${ }^{* * *}$
}

\section{INTRODUÇÃO}

A essência do imaginário está no ato de vislumbrar nos semblantes do tempo os trajetos desenhados pelo homem para afirmar e reafirmar sua condição racional. Racionalidade está que se acentua quando tratamos da gama de dispositivos simbólicos que o homem utiliza e, por vezes, atualiza para imprimir sua marca identitária. Essa marca ainda assim não é sólida, com o passar do tempo ela passa por vários processos, se dissolve, se expande, se homogeneíza de tal forma que acaba sendo camuflada pelo turbilhão de semas que transbordam a bacia semântica do imaginário de modo que alguns são até esquecidos.

\section{SITUANDO A MATERIALIDADADE}

O objeto em análise consiste em uma entrevista intitulada "Indígenas fazem bloqueios em rodovias em protesto contra a PEC 215”, exibida pelo RBS Notícias no dia 11 de novembro de 2015. A reportagem veiculada possui apenas um minuto e dezesseis segundos, tempo suficiente para apresentar as manifestações que ocorreram nas rodovias BR101 em Palhoça, BR- 158 em Chapecó e SC- 480 no trecho que faz divisa com o estado do Rio Grande do Sul, situadas em diferentes regiões de Santa Catarina.

Os protestos realizados pelos indígenas objetivam reclamar a possível mudança de autoridade para demarcação dos territórios indígenas. Poder esse que até o momento era exercido pela União e passaria a ser executado pelo poder Legislativo.

Para tanto, o modo como foi pensada a manifestação, as frases impressas nos cartazes, às vestimentas retiradas e as mantidas, os instrumentos selecionados (lança, cocar,

\footnotetext{
** Doutora. Docente do Programa de Pós-Graduação em Ciências da Linguagem - Universidade do Sul de Santa Catarina. E-mail: heloisapreis@ @otmail.com.

*** Doutoranda no Programa de Pós-Graduação em Ciências da Linguagem - Universidade do Sul de Santa Catarina. E-mail: ley_ddy@hotmail.com
} 
instrumentos musicais), as pinturas corporais, os cantos e danças executados em círculo/roda, serão percebidos a partir da teoria do Imaginário considerando as perspectivas dos grupos indígenas em relação à escolha das estratégias utilizadas para reafirmarem a sua condição.

Após a definição de tais elementos, realizamos um detalhado exame a fim de comparar com traços elementais tratados na teoria idealizada por Gilbert Durand ao propor seus estudos de Imaginário. Os conceitos de estereótipo e pregnância simbólica propostos por Felinto (2003), também contribuíram para a compreensão da percepção indígena acerca da sociedade e, nesse mesmo movimento, a percepção da sociedade em relação aos grupos indígenas. Os escritos de Pitta (2005), Legros (2007) e Teixeira (2013), também embasaram as formulações de Imaginário e sociedade. Ambas, as referências citadas, agregadas ao viés do Regime noturno da Imagem abordado por Gilbert Durand em sua obra "As Estruturas Antropológicas do Imaginário", publicada no ano de 2002, balizaram nossa percepção analítica.

Considerando que a materialidade é um texto cultural, a leitura do objeto se fará pela vertente metodológica da mitocrítica. Ferreira-Santos e Almeida (2012) apresentam a mitocrítica como sendo "uma técnica de investigação que parte das obras literárias, artísticas, dos relatos, histórias de vida, documentos e narrativas de modo geral para depreender os mitos diretores dessas produções". Os autores ainda enfatizam que há um relato mítico inerente à significação de todo relato reafirmando as proposições de Durand no que confere a estrutura do mito.

A utilização dessa técnica permitirá "compreender que uma obra estrutura-se a partir de símbolos, de recorrências simbólicas, que em seu conjunto revelam a ligação da obra a um mito, ainda que este sofra os desgastes do tempo e se apresente camuflado ou mesmo em partes, ou seja, apenas como alguns mitemas" (FERREIRA-SANTOS E ALMEIDA, 2012, p. 115). Da mesma forma favorecera a identificação dos elementos simbólicos que foram acessados pelos índios na busca por reafirmarem sua condição.

\section{ALGUNS APORTES SOBRE OS REGIMES DA IMAGEM}

Durand (2002) propõe que, para entendermos as grandes constelações simbólicas que fundamentam o Imaginário, precisamos compreender as estruturas que fundamentam os dois grandes regimes da imagem: o Diurno e o Noturno. 
O Regime Diurno tem a ver com a dominante postural, a tecnologia das armas, a sociologia do soberano mago e guerreiro, os rituais de elevação e purificação; o Regime Noturno subdividi-se nas dominantes digestiva e cíclica, a primeira subsumindo as técnicas do continente e do hábitat, os valores alimentares e digestivos, a sociologia matriarcal e alimentadora, a segunda agrupando as técnicas do ciclo, do calendário agrícola e da indústria têxtil, os símbolos naturais ou artificiais do retorno, os mitos, e os dramas astrobiológicos (DURAND, 2002, p. 58).

O autor destaca que "o Regime Diurno da imagem define-se, portanto, de uma maneira geral, como o regime da antítese. Desse modo, devemos partir de uma concepção simbólica de imaginação que priorize o semantismo das imagens e o poder que elas têm de produzir sentido". O Regime Diurno, postulado por Durand (2002, p. 179) pode ser compreendido como o

Regime específico da imagem, caracterizados por constelações simbólicas, todas polarizadas em torno de dois grandes esquemas, diairético e ascensional, e do arquétipo da luz. É com efeito o gesto diarético que parece subentender todo esse regime da representação [...]. E pode-se dizer que a atualização do Regime Diurno da imagem se faz pelo gládio e pelas atitudes imaginárias diairéticas. O Regime Diurno é, portanto, essencialmente polêmico. A figura que o exprime é a antítese $[\ldots]$.

Ao fundamentar o Regime Diurno pelo viés da dominante postural, Turchi (2003) sugere que podemos situá-lo "à tecnologia das armas, à sociologia do soberano mago e guerreiro, aos rituais da elevação e da purificação" e, acrescenta que "Com a noção do trajeto antropológico, Durand conecta o pólo subjetivo, da natureza humana, e o pólo objetivo, das manifestações culturais que se relacionam através dos esquemas, dos arquétipos e dos símbolos".

O Regime Noturno da Imagem surge da inversão dos valores atribuídos aos termos da antítese, dessa forma, Turchi (2003), propõe que a imaginação passa a desenvolver "uma outra atitude imaginativa que consiste em captar as forças vitais do devir, transmutando os aspectos tenebrosos do tempo em virtudes benéficas".

O Regime Noturno é fundamentado por Durand através das estruturas míticas e sintéticas produzidas a partir de um conjunto símbolos.

Nos dois grupos há valorização do regime noturno das imagens, mas num dos casos a valorização é fundamental e inverte o conteúdo afectivo das imagens: é então que no seio da própria noite, o espírito procura a luz e a queda se eufemiza em descida e o abismo minimiza-se em taça, enquanto no outro caso, a noite não passa de propedêutica necessária ao dia, promessa indubitável da aurora (TURCHI, p. 2003). 
Neste regime, as alegorias são impressas por símbolos que reforçam o temor a tudo que contradiz a luz e o dia. Teme-se o que não se pode ver e o que está por vir e que se oculta na noite que se prolonga à medida que o emaranhado de símbolos se agrupa e fortalece esse imaginário.

\section{OS DISPOSITIVOS SIMBÓLICOS: A REAFIRMAÇÃO DA CONDIÇÃO INDÍGENA}

As inúmeras transformações culturais e sociais ocorridas na sociedade tem proporcionado diversas consequências nos modos de vida dos indivíduos. Como consequência dessas transformações torna-se necessário que os indivíduos realizem certo esforço no sentido de se adaptarem ao contexto social vigente.

Nesse movimento, o processo de significação das nossas práticas sociais e culturais é diretamente afetado e, em muitos momentos, acaba sendo ressignificado e atualizado. Tal situação pode ser observada na manifestação realizada pelos grupos indígenas em alguns municípios de Santa Catarina durante o protesto contra a aprovação da PEC 215 que sugere que o poder de demarcação do território indígena passe ao Legislativo.

Na matéria exibida pelo RBS Notícias, no dia 11 de novembro de 2015, os indígenas utilizaram elementos culturais simbólicos para reafirmarem sua condição. Deste modo, os índios aparecem sem camisa, com colares, cocares, instrumentos musicais, lanças, descalços, ainda que também com sapatos e calças jeans, dançando em círculo.

Os indígenas buscaram nestes símbolos (artefatos, colares, instrumentos musicais, cocares e lanças, vestimentas de palha) a reafirmação da sua condição de fato por acreditarem na potência imagética e na repercussão que esses aparatos proporcionariam. Durand (2002, p. 54), salienta que "esta "dupla entrada" que os objetos propõem concede, assim, uma enorme liberdade à interpretação tecnológica dos utensílios e que esse caráter de polivalência de interpretação acentua-se ainda nas transposições imaginárias".

A estratégia dos indígenas foi utilizar esses dispositivos simbólicos no intuito de reativar na memória dos telespectadores e dos demais que acompanharam as manifestações, a imagem primeira, a matriz arquetipal que eles representam. Proposito este que é reforçado pelo discurso do cacique da aldeia Toldo Chimbangue, Idalino Fernandes: "Esse manifesto é para mostrar para o governo e para os parlamentares que nós estamos vivos e não queremos que nossos direitos sejam violados". 
De modo que, antes de pensarem no protesto em si, os indígenas refletiram como eles se 'apresentariam' durante a manifestação idealizando uma visibilidade que causasse um efeito de sentido de reconhecimento da condição indígena. A utilização de elementos culturais que nem são mais tão relevantes (ou presentes) para alguns grupos, sugere a necessidade de buscar comportamentos e acessórios que permeiam a construção de um imaginário social acerca dos índios. Buscar o resgate de uma imagem que já é perpetuada culturalmente tornase necessária a reafirmação do guerreiro.

As lanças, o andar em círculo, os gritos de guerra, agora também manifestados em cartazes, imprimindo a posição de guerreiros, demarcando seu território, expressando sua disposição para o combate e defesa dos seus direitos, são sinalizadas por todos e trazem à tona os traços elementais que caracterizavam o índio primitivo em sua essência.

Nesse sentido, considera-se que não basta apenas protestar, é necessário inicialmente reafirmar a importância de quem está protestando. Um 'ser' índio que possui traços físicos e certidão de nascimento, mas um ser índio que também é brasileiro e pertence a essa nação conforme sugeriu uma das faixas utilizadas pelos indígenas que dizia: "Somos nação brasileira... Somos povos originários dessa terra...Não a PEC do Genocídio”.

Um ser índio que dá sua contribuição à sociedade, mas que tem que se utilizar de traços elementais diversos para mostrar sua identidade, para instigar o resgate da figura indígena e o que eles representam no Imaginário Social vigente.

Os indígenas recorrem a uma autenticidade encenada amparada em diversos dispositivos com o intuito de neutralizar as inúmeras transformações culturais ocorridas em seu próprio meio cultural e revisitam seus contextos/marcas culturais mais antigos para ativar no imaginário social da sociedade vigente quem eles são, sua origem e importância.

Assim, as marcas que evidenciam a condição indígena são acessadas na busca por expressar uma identidade indígena, que luta com armas primitivas - repletas de simbologias que ilustram a sua força, sua história e sua cultura - , que está amparada nas leis e reclama os seus direitos, mas que ainda necessita recorrer aos dispositivos símbolos presentes no imaginário social para fazerem-se reconhecidas.

\section{REFERÊNCIAS}

CASSIRER, Ernst. Ensaio sobre o homem: introdução a uma filosofia da cultura humana. - São Paulo: Martins Fontes, 1994.

CRIPPA, Adolfo. Mito e cultura. São Paulo: Convívio, 1975. 
DURAND, Gilbert. Sobre a exploração do imaginário, seu vocabulário, métodos e aplicações transdiciplinares: mito, mitanálise e mitocritica. R. Fac. Educ., 11 (1/2): 243-273, 1985.

DURAND, Gilbert. As estruturas antropológicas do imaginário: introdução à arquetipologia geral. São Paulo: Martins Fontes, 2002.

FELINTO, Erick. Novas tecnologias, antigos mitos: apontamentos para uma definição operatória de imaginário tecnológico. Galáxia. n.6. out. 2003. p. 165-188.

FERREIRA-SANTOS, Marcos; ALMEIDA, Rogério de. Aproximações ao Imaginário: bússola de investigação poética. São Paulo, Képos, 2012.

TURCHI, Maria Zaira. Literatura e antropologia do imaginário. Brasília: Universidade de Brasília, 2003. 